\title{
Is intrathoracic tracheal collapsibility correlated to clinical phenotypes and sex in patients with COPD?
}

This article was published in the following Dove Press journal:

International Journal of COPD

28 April 2015

Number of times this article has been viewed

\section{Gianna Camiciottoli' \\ Stefano Diciotti ${ }^{2}$ \\ Francesca Bigazzi' \\ Simone Lombardo ${ }^{3}$ \\ Maurizio Bartolucci ${ }^{4}$ \\ Matteo Paoletti' \\ Mario Mascalchi ${ }^{3}$ \\ Massimo Pistolesi'}

'Section of Respiratory Medicine, Department of Clinical and

Experimental Medicine, University of Florence, Florence, Italy;

${ }^{2}$ Department of Electrical,

Electronic, and Information

Engineering "Guglielmo Marconi,"

University of Bologna, Cesena,

Italy; ${ }^{3}$ Radiodiagnostic Section,

Department of Clinical and

Experimental Biomedical Sciences,

University of Florence, Florence,

Italy; ${ }^{4}$ Department of Diagnostic

Imaging, Careggi University Hospital, Florence, Italy
Correspondence: Gianna Camiciottoli Pulmonary Pathophysiology Unit, Department of Clinical and Experimental Medicine, University of Florence, Largo Brambilla 3, Florence 50I34, Italy Tel +393476733664

Email gianna.camiciottoli@unifi.it
Abstract: A substantial proportion of patients with chronic obstructive pulmonary disease (COPD) develops various degree of intrathoracic tracheal collapsibility. We studied whether the magnitude of intrathoracic tracheal collapsibility could be different across clinical phenotypes and sex in COPD. Intrathoracic tracheal collapsibility measured at paired inspiratoryexpiratory low dose computed tomography $(\mathrm{CT})$ and its correlation with clinical, functional, and CT-densitometric data were investigated in 69 patients with COPD according to their predominant conductive airway or emphysema phenotypes and according to sex. Intrathoracic tracheal collapsibility was higher in patients with predominant conductive airway disease $(n=28)$ and in females $(n=27)$. Women with a predominant conductive airway phenotype $(n=10)$ showed a significantly greater degree of collapsibility than women with predominant emphysema $(28.9 \% \pm 4 \%$ versus $11.6 \% \pm 2 \% ; P<0.001)$. Intrathoracic tracheal collapsibility was directly correlated with inspiratory-expiratory volume variation at CT and with forced expiratory volume (1 second), and inversely correlated with reduced CT lung density and functional residual capacity. Intrathoracic tracheal collapsibility was not correlated with cough and wheezing; however, intrathoracic tracheal collapsibility and clinical phenotypes of COPD are closely correlated. In patients with a predominant emphysematous phenotype, a reduced collapsibility may reflect the mechanical properties of the stiff hyperinflated emphysematous lung. The high collapsibility in patients with predominant airway disease, mild airway obstruction, and in women with this phenotype may reflect chronic airway inflammation. The lack of relationship with such symptoms as wheezing, cough, and dyspnea could indicate that intrathoracic tracheal collapsibility itself should be considered neither an abnormal feature of COPD nor a relevant clinical finding.

Keywords: airway, computed tomography, lung density, pulmonary function, lung volumes

\section{Introduction}

Intrathoracic tracheal collapsibility refers to an expiratory collapse of the intrathoracic trachea due to tracheal wall weakness caused by reduction and atrophy of the pars membranacea longitudinal and elastic fibers, with consequent anterior bulging of the trachea posterior wall and/or impaired cartilage integrity. ${ }^{1-5}$ Various degrees of expiratory tracheal collapse can occur, up to tracheomalacia, when the reduction of intrathoracic tracheal cross-sectional area at computed tomography (CT) is more than $50 \%{ }^{4}$ As well as some primary congenital syndromes such as polychondritis and Mounier-Kuhn disease, several acquired conditions associated with intrathoracic tracheal collapsibility have been described in adults. ${ }^{1-3}$

A substantial proportion of patients with chronic obstructive pulmonary disease (COPD) could develop various degrees of airway collapsibility ${ }^{6}$ due to chronic inflammation and irritant exposure, instability of the tracheal wall due to the loss of 
parenchymal elastic fibers, and repeated mechanical stress from coughing. ${ }^{1-3}$ Definite relationships of intrathoracic tracheal collapsibility have not been established, either with clinical symptoms and pulmonary function testing or with CT quantitative data of lung density and airway wall thickness. ${ }^{6-7}$ Furthermore, it remains unclear whether tracheal collapsibility should or should not be considered an associated pathological finding of COPD. As a matter of fact, unexpectedly high degrees of intrathoracic tracheal collapsibility have been shown to be present also in normal asymptomatic subjects. ${ }^{8}$

We studied intrathoracic tracheal collapsibility in a group of patients with COPD and assessed whether its magnitude could be related to clinical features of the disease, to predominant conductive airway disease or predominant emphysema clinical characteristics, to pulmonary function, and to CT densitometric data. Because women with COPD have been reported to display different clinical manifestations of the disease such as more frequent exacerbations, more severe dyspnea, more frequent cough, and increased sputum production than men, ${ }^{9-11}$ we studied whether the magnitude of tracheal collapsibility in COPD could differ according to sex.

\section{Methods}

\section{Patients}

Sixty-nine outpatients with COPD (42 males) were consecutively enrolled and completed the study. The study was approved by the hospital ethics committee, and informed written consent was obtained from all patients. We included patients aged 40-85 years, who were smokers or former smokers with a smoking history of at least 10 pack-years. COPD was defined according to a postbronchodilator forced expiratory volume ( 1 second) $\left(\mathrm{FEV}_{1}\right) /$ forced vital capacity $<0.70$ and not reversible airflow obstruction after bronchodilation. ${ }^{12}$ We excluded subjects who had an exacerbation within 3 months or those who had clinical conditions that could interfere with the assessment of pulmonary function or chest CT quantitative parameters, including asthma, a history of upper airway obstruction, diffuse bronchiectasis, cystic fibrosis, interstitial lung disease, acute heart failure, chemoradiation therapy, lung cancer, lung surgery, known or suspected pregnancy, and metal objects in the chest.

Patients' evaluation consisted of thorough clinical history, physical examination, whole pulmonary function testing, and inspiratory and expiratory CT scan. Dyspnea severity was assessed by the modified Medical Research Council (mMRC) dyspnea scale. Static and dynamic lung volumes and single breath diffusing capacity for carbon monoxide $\left(\mathrm{DL}_{\mathrm{CO}}\right)$ were measured by a mass-flow sensor and a multigas analyser (V6200 Autobox body plethysmograph; SensorMedics, Yorba Linda, CA, USA) according to American Thoracic Society/ European Respiratory Society guidelines and expressed as percentage of the predicted values. ${ }^{12}$ Each patient was assigned either a predominant airway or a predominant emphysema clinical phenotype according to a multivariate model based on sputum characteristics and lung function variables, which was validated by quantitative CT. ${ }^{13}$ The variables entered to classify patients according to the predominant mechanism of airflow limitation were linearly combined to determine the relative predominance of conductive airway (negative value) or emphysema phenotype (positive value) in each patient according to the following computation: ${ }^{13}$

$$
\begin{gathered}
\left(-0.018 \times \mathrm{DL}_{\mathrm{CO}} \%\right)+(-0.580 \times \text { purulent sputum })+ \\
(0.011 \times \text { total lung capacity } \%)+0.324
\end{gathered}
$$

where purulent sputum was entered as 1 when present or 0 when absent. Phenotypes and sex subgroups were matched for age.

\section{Imaging assessment}

CT examinations were performed on a 16-detector row scanner (Sensation 16, Siemens, Munich, Germany) using a detector configuration of $16 \times 0.75 \mathrm{~mm}, 140 \mathrm{kVp}, 150$ effective mAs, tube rotation time of $750 \mathrm{~ms}$, and a pitch of 1.5. Two spiral acquisitions were obtained from the apex to the base during breath-hold at full inspiration and at the end of maximal expiration, respectively. Before undergoing CT scanning, patients were coached by a pulmonologist to hold their breath at full inspiration and full expiration ${ }^{7}$ and trained to perform inspiratory and expiratory vital capacity maneuvers while lying on the CT examination bed. The acquisition time was 8-12 seconds. For whole lung optimized densitometry, we obtained thick (5 mm) slices with smooth filter (B31S) and $5 \mathrm{~mm}$ reconstruction increment. ${ }^{14}$ For visual qualitative assessment, we used thin $(1 \mathrm{~mm})$ slices with sharp filter (B70S) and $1 \mathrm{~mm}$ reconstruction increment. ${ }^{14}$ The system was calibrated daily with air. ${ }^{15}$ No intravenous contrast material was administered. Inspiratory and expiratory whole lung volumes were automatically measured after lung segmentation (Figure $1 \mathrm{~A}$ and B) and delta volume was calculated by the following computation:

$$
\frac{\text { Inspiratory CT volume - Expiratory CT volume }}{\text { Inspiratory CT volume }}
$$

Intrathoracic tracheal collapsibility was assessed by an algorithm for trachea segmentation (Figure 1C and D) 

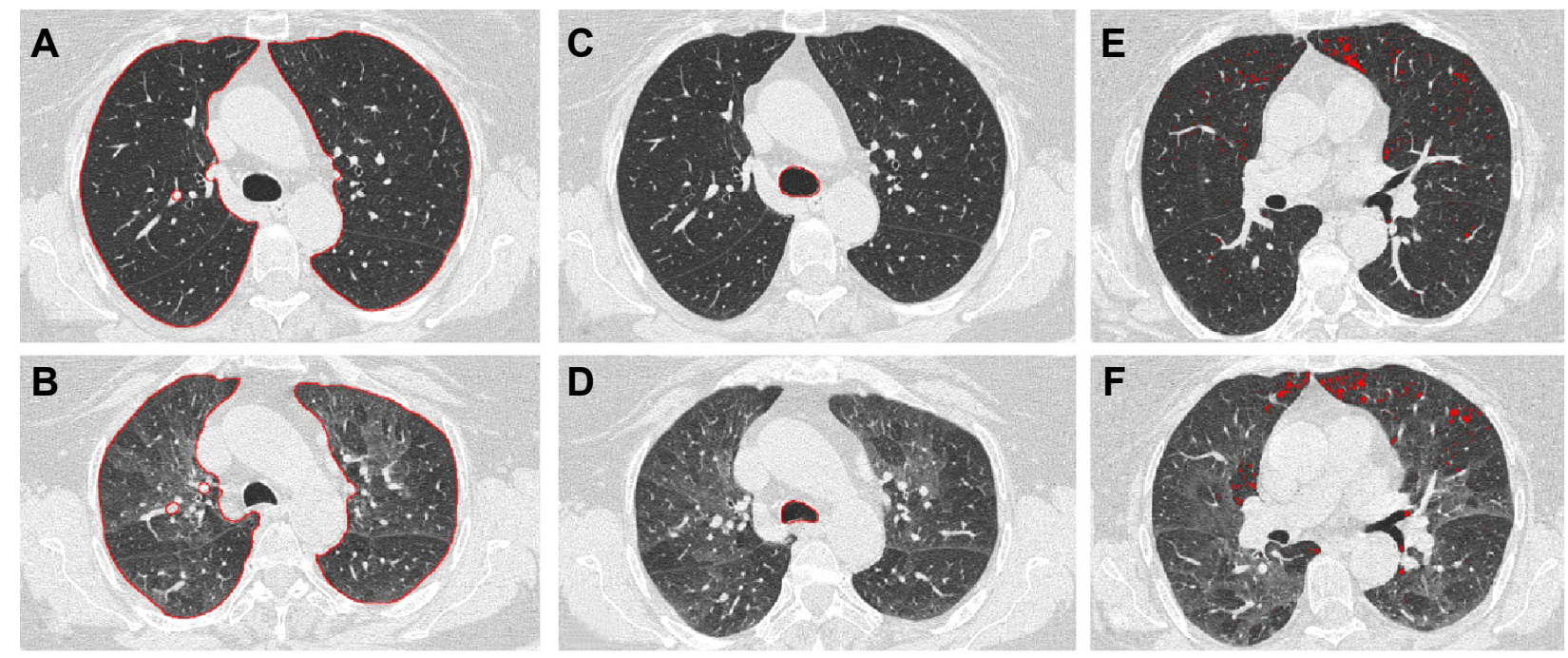

Figure I Application of the proposed algorithms on the CT scans of a COPD patient.

Notes: For the sake of simplicity, the results (in red) are superimposed on a CT slice at about I cm above the carina (A-D) and at a lower level (E and F). Inspiratory CT slices are shown on the top row, whereas corresponding expiratory CT slices are on the bottom row. Panels $\mathbf{A}$ and $\mathbf{B}$ show the lung segmentation results employed for lung volume computation (delta volume $=0.42$ ). Panels $\mathbf{C}$ and $\mathbf{D}$ show trachea segmentation results used to measure tracheal collapsibility (35.8\%). Panels $\mathbf{E}$ and $\mathbf{F}$ display the lung area with

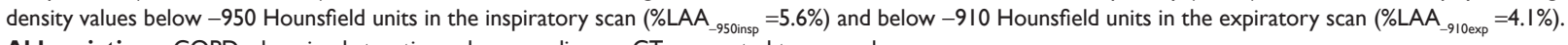

Abbreviations: COPD, chronic obstructive pulmonary disease; CT, computed tomography.

entailing the following steps: 1) gray-level thresholding of the CT image; 2) three-dimensional connected component labeling to select lungs, trachea, and main bronchi; and 3) using a region-growing procedure to extract a $5 \mathrm{~cm}$ length of trachea starting from $1 \mathrm{~cm}$ above the carina. The volume of the selected tracheal segment was calculated for inspiratory (inspTV) and expiratory (expTV) CT scans. Intrathoracic tracheal collapsibility was measured according to the following computation: ${ }^{16}$

$$
\frac{\text { InspTV }- \text { ExpTV }}{\text { Insp TV }} \times 100
$$

To obtain whole lung densitometric data we utilized a software program that automatically determines the boundaries of each lung ${ }^{17}$ and the percentage of total lung area with density values below -950 Hounsfield units in the inspiratory scan and below -910 Hounsfield units in the expiratory scan (\% $\mathrm{LAA}_{-950 \text { insp }}$ and \% $\mathrm{LAA}_{-910 \mathrm{exp}}$, respectively) (Figure 1E and F). These density thresholds have been demonstrated to be correlated with the anatomic extent of emphysema in the inspiratory and expiratory chest CT scan. ${ }^{18}$ Bronchial wall thickness was measured by means of an electronic caliper according to a previously published method. ${ }^{19}$ As bronchial tree dimensions depend on subjects height and sex, the bronchial wall thickness was normalized in each patient by plotting the square root of the airway wall area against the internal perimeter of each measurable airway. The resulting regression line was used to predict the square root of the wall area for an ideal airway with an internal perimeter of $10 \mathrm{~mm}$ and to calculate its average wall thickness (AWTPi10) representing the distal airways compartment in COPD. ${ }^{13}$

\section{Statistical analysis}

Data are presented as means \pm standard deviation for continuous variables and as counts and proportions for nominal and ordinal variables. Pearson's correlation coefficients were used to study the association between quantitative variables; $t$-test and ANOVA were used to compare the means of continuous variables among different subsets of patients. Fisher's exact test was used to compare the prevalence of categorical variables among different subsets of patients. Significance was set at $P<0.05$. A multivariate analysis was performed to estimate tracheal collapsibility (dependent variable) using functional, clinical, and CT data as independent variables. In each of the examined subsets of patients the most significant model with the least number of variables was selected by a forward stepwise process. Parameters were entered or removed from the process according to $F$-statistics.

\section{Results}

\section{Patient features}

Anthropometric, smoke exposure, and functional and quantitative CT data of the recruited patients are displayed in Tables 1 and 2 . Among the 69 patients, 28 were classified as being affected by predominant airway disease and 41 by predominant 
Table I Anthropometric data, smoke exposure, pulmonary function, and presence of purulent sputum in 69 patients with COPD subdivided according to the predominant mechanism of air flow limitation and sex

\begin{tabular}{|c|c|c|c|c|c|c|c|}
\hline & $\begin{array}{l}\text { All patients } \\
(n=69)\end{array}$ & $\begin{array}{l}\text { Predominant airway } \\
\text { phenotype }(n=28)\end{array}$ & $\begin{array}{l}\text { Predominant emphysema } \\
\text { phenotype }(n=4 I)\end{array}$ & $P$ & $\begin{array}{l}\text { Males } \\
(n=42)\end{array}$ & $\begin{array}{l}\text { Females } \\
(n=27)\end{array}$ & $P$ \\
\hline Age (years) & $67 \pm 9$ & $66 \pm 8$ & $66 \pm 10$ & NS & $67 \pm 9$ & $66 \pm 9$ & NS \\
\hline BMI $\left(\mathrm{kg} / \mathrm{m}^{2}\right)$ & $25 \pm 4$ & $27 \pm 4$ & $24 \pm 4$ & $<0.01$ & $25 \pm 4$ & $25 \pm 4$ & NS \\
\hline Packs/year & $42 \pm 23$ & $35 \pm 24$ & $47 \pm 22$ & $<0.05$ & $4 I \pm 18$ & $44 \pm 30$ & NS \\
\hline $\mathrm{FEV}_{1} \%$ & $61 \pm 27$ & $73 \pm 23$ & $53 \pm 26$ & $<0.001$ & $54 \pm 25$ & $73 \pm 25$ & $<0.01$ \\
\hline FRC\% & $|26 \pm 3|$ & $111 \pm 25$ & $137 \pm 30$ & $<0.001$ & $13 \mid \pm 33$ & $120 \pm 24$ & NS \\
\hline $\mathrm{DL}_{\mathrm{CO}} \%$ & $69 \pm 22$ & $85 \pm 18$ & $57 \pm 16$ & $<0.0001$ & $67 \pm 22$ & $69 \pm 21$ & NS \\
\hline Presence of purulent sputum & $16 / 69$ & $12 / 28$ & $4 / 41$ & $<0.01$ & $11 / 42$ & $5 / 27$ & NS \\
\hline
\end{tabular}

Notes: Data are mean \pm SD for continuous variables and proportion for categorical values. Sputum purulence (entered as $\mathrm{I}$ when present and 0 when absent in the regression equation employed to phenotype patients with COPD). Packs/year is the mean number of daily cigarettes $\times$ number of years/20.

Abbreviations: BMI, body mass index (weight/height ${ }^{2}$ ); COPD, chronic obstructive pulmonary disease; $\mathrm{DL}_{\mathrm{co}} \%$, lung diffusing capacity for carbon monoxide (\% of predicted); $\mathrm{FEV}, \%$, forced expiratory volume in one second (\% of predicted); FRC\%, functional residual capacity (\% of predicted); NS, not significant; SD, standard deviation.

emphysema. ${ }^{13}$ Patients with predominant emphysema had a significantly higher smoking exposure and lower body mass index (BMI). They also showed a significantly higher degree of airflow obstruction, hyperinflation, and $\mathrm{DL}_{\mathrm{CO}}$ reduction. AWTPi10 did not significantly differ between the two subgroups.

\section{Relationship between intrathoracic tracheal collapsibility and clinical, functional, and CT variables}

Patients with predominant airway disease had a higher intrathoracic tracheal collapsibility than patients with predominant emphysema (Table 2).

The relationships between intrathoracic tracheal collapsibility and lung function parameters are reported in Table 3. Table 4 shows the relationship of intrathoracic tracheal collapsibility and $\mathrm{CT}$ expiratory and inspiratory density expressed as \% $\mathrm{LAA}_{-910 \text { exp }}$ and \% $\mathrm{LAA}_{-950 \text { insp }}$, respectively. Intrathoracic tracheal collapsibility was positively, although weakly, correlated with $\mathrm{FEV}_{1}$, negatively correlated with functional residual capacity ( $\%$ of predicted) (FRC\%) in the whole set, and more strongly in patients with predominant emphysema. Intrathoracic tracheal collapsibility was negatively correlated with \% $\mathrm{LAA}_{-910 \exp }$ and \% $\mathrm{LAA}_{-950 \text { insp }}$ in the whole sample and in each subset. Figure 2 shows the positive relationships between changes in lung volume measured at $\mathrm{CT}$ from maximal inspiration to maximal expiration and intrathoracic tracheal collapsibility in the whole sample and each subset.

\section{Relationship between intrathoracic tracheal collapsibility and symptoms}

No correlation was found between intrathoracic tracheal collapsibility and the following variables: wheezing in the whole group of patients (mean intrathoracic tracheal collapsibility in patients with wheezing: $11 \pm 2$; mean intrathoracic tracheal collapsibility in patients without wheezing: $16 \pm 2, P=0.16$ ); predominant airway disease (mean intrathoracic tracheal collapsibility in patients with wheezing: $13 \pm 3$; mean intrathoracic tracheal collapsibility in patients without wheezing: $22 \pm 3, P=0.08$ ); predominant emphysema (mean intrathoracic

Table 2 CT quantitative densitometric data, airway wall thickness, inspiratory-expiratory volume variation, and tracheal collapsibility in 69 patients with COPD subdivided according to the predominant mechanism of air flow limitation and sex

\begin{tabular}{|c|c|c|c|c|c|c|c|}
\hline & $\begin{array}{l}\text { All patients } \\
(n=69)\end{array}$ & $\begin{array}{l}\text { Predominant airway } \\
\text { phenotype }(n=28)\end{array}$ & $\begin{array}{l}\text { Predominant emphysema } \\
\text { phenotype }(n=4 I)\end{array}$ & $P$ & $\begin{array}{l}\text { Males } \\
(n=42)\end{array}$ & $\begin{array}{l}\text { Females } \\
(n=27)\end{array}$ & $P$ \\
\hline$\%_{\text {LAA }}$-950insp & $11.7 \pm 13$ & $5 \pm 5$ & $16.3 \pm 15$ & $<0.001$ & $15 \pm 15$ & $7 \pm 8$ & $<0.05$ \\
\hline$\%$ LAA $_{-910 \exp }$ & $12.7 \pm 15$ & $4 \pm 0.1$ & $16.9 \pm 16$ & $<0.01$ & $16 \pm 16$ & $7 \pm 11$ & $<0.05$ \\
\hline AWTPilO (mm) & $3.84 \pm 0.11$ & $3.85 \pm 0.12$ & $3.83 \pm 0.08$ & NS & $3.87 \pm 0.09$ & $3.80 \pm 0.09$ & $<0.05$ \\
\hline Delta volume & $0.30 \pm 0.13$ & $0.36 \pm 0.10$ & $0.26 \pm 0.13$ & 0.001 & $0.29 \pm 0.14$ & $0.32 \pm 0.10$ & NS \\
\hline Tracheal collapsibility (\%) & $14.4 \pm 12$ & $19 \pm 13$ & $11.4 \pm 10$ & $<0.01$ & $12 \pm 10$ & $18 \pm 14$ & $<0.05$ \\
\hline
\end{tabular}

Notes: Data are mean \pm SD. Delta volume is ([inspiratory CT volume - expiratory CT volume]/inspiratory CT volume). Intrathoracic tracheal collapsibility (\%) is ([inspiratory tracheal volume - expiratory tracheal volume]/inspiratory tracheal volume) $\times 100$.

Abbreviations: AWTPilO (mm), average wall thickness of an extrapolated airway with an internal perimeter of $10 \mathrm{~mm}$; COPD, chronic obstructive pulmonary disease; CT, computed tomography; \%LAA ${ }_{-910 x p}$, percentage of total lung area with attenuation values below -910 Hounsfield units at maximal expiration; \%LAA -950insp percentage of total lung area with attenuation values below -950 Hounsfield units at maximal inspiration; NS, not significant; SD, standard deviation. 
Table 3 Relationships of intrathoracic tracheal collapsibility with functional parameters indicative of airflow obstruction and hyperinflation

\begin{tabular}{|c|c|c|c|c|c|}
\hline $\begin{array}{l}\text { Intrathoracic tracheal } \\
\text { collapsibility (\%) }\end{array}$ & $\begin{array}{l}\text { All patients } \\
(n=69)\end{array}$ & $\begin{array}{l}\text { Predominant airway } \\
\text { phenotype }(n=28)\end{array}$ & $\begin{array}{l}\text { Predominant emphysema } \\
\text { phenotype }(n=4 I)\end{array}$ & $\begin{array}{l}\text { Males } \\
(n=42)\end{array}$ & $\begin{array}{l}\text { Females } \\
(n=27)\end{array}$ \\
\hline \multirow[t]{2}{*}{$\mathrm{FEV}_{1} \%$} & $r=0.44$ & $r=0.39$ & $r=0.37$ & $r=0.32$ & $r=0.49$ \\
\hline & $P<0.000 I$ & $P<0.05$ & $P<0.05$ & $P<0.05$ & $P<0.05$ \\
\hline \multirow[t]{2}{*}{ FRC\% } & $r=-0.43$ & NS & $r=-0.54$ & $r=-0.57$ & NS \\
\hline & $P<0.001$ & & $P<0.00$ I & $P<0.000$ I & \\
\hline
\end{tabular}

Abbreviations: $\mathrm{FEV}, \%$, forced expiratory volume in one second (\% of predicted); FRC\%, functional residual capacity (\% of predicted); NS, not significant.

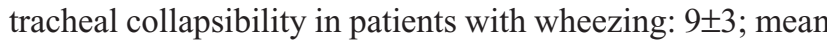
intrathoracic tracheal collapsibility in patients without wheezing: $12 \pm 2, P=0.44$ ); male sex (mean intrathoracic tracheal collapsibility in patients with wheezing: $9 \pm 2$; mean intrathoracic tracheal collapsibility in patients without wheezing: $14 \pm 2, P=0.16$ ); female sex (mean intrathoracic tracheal collapsibility in patients with wheezing: $18 \pm 3$; mean intrathoracic tracheal collapsibility in patients without wheezing: $17 \pm 5, P=0.77$ ); cough in the whole group of patients (mean intrathoracic tracheal collapsibility in patients with cough: $15 \pm 2$; mean intrathoracic tracheal collapsibility in patients without cough: $11 \pm 3, P=0.25$ ); predominant emphysema phenotype (mean intrathoracic tracheal collapsibility in patients with cough: $12 \pm 2$; mean intrathoracic tracheal collapsibility in patients without cough: $11 \pm 3, P=0.81$ ); male sex (mean intrathoracic tracheal collapsibility in patients with cough: $12 \pm 1$; mean intrathoracic tracheal collapsibility in patients without cough: $12 \pm 6, P=0.96$ ); female sex (mean intrathoracic tracheal collapsibility in patients with cough: $21 \pm 3$; mean intrathoracic tracheal collapsibility in patients without cough: $10 \pm 3, P=0.08$ ). All patients with predominant airway disease had productive cough with no different magnitude of intrathoracic tracheal collapsibility in relation to sputum purulence ( $18 \pm 3$ in patients with purulent sputum and $20 \pm 4$ in patients with no purulent sputum, $P=0.72$ ). On the contrary, mMRC dyspnea score was significantly higher in patients with an emphysema phenotype of COPD and a lower degree of intrathoracic tracheal collapsibility with respect to patients with predominant airway disease (mean mMRC 2.2 \pm 0.2 and $1.2 \pm 0.2$, respectively, $P<0.01)$.

\section{Relationship between intrathoracic tracheal collapsibility and sex}

Females with COPD were less severe, had less severe reduction in \% LAA $_{-950 \text { insp }}$ and \%LAA_-910exp , lower AWTPi10, and a significantly higher degree of tracheal collapsibility with respect to males (Tables 1 and 2). The proportion of the two COPD phenotypes was the same in males and females (24/18 predominant emphysema/predominant airway disease among males respectively; 17/10 predominant emphysema/ predominant airway disease among females; Fisher's exact test $P=0.8$, not significant). Women with predominant airway disease showed a significantly greater degree of tracheal collapsibility than women with predominant emphysema phenotype $(28.9 \% \pm 4 \%$ versus $11.6 \% \pm 2 \%, P<0.001)$. No difference in intrathoracic tracheal collapsibility was found in the two predominant phenotypes $(13.2 \% \pm 2 \%$ in predominant airway disease versus $11.2 \% \pm 2 \%$ in predominant emphysema, $P=0.26$ ) in males (Figure 3).

\section{Multivariate analysis}

The results of multivariate analysis in the whole set of patients, in predominant airway and predominant emphysema phenotypes, in males and in females are reported in Table 5. Delta volume is the parameter that in all subsets described most of the variance of tracheal collapsibility.

Table 4 Relationships of intrathoracic tracheal collapsibility with CT thresholds of lung inspiratory and expiratory density (\% LAA $_{-950 i n s p}$ and \%LAA ${ }_{-910 \text { exp }}$, respectively)

\begin{tabular}{|c|c|c|c|c|c|}
\hline $\begin{array}{l}\text { Intrathoracic tracheal } \\
\text { collapsibility (\%) }\end{array}$ & $\begin{array}{l}\text { All patients } \\
(n=69)\end{array}$ & $\begin{array}{l}\text { Predominant airway } \\
\text { phenotype }(n=28)\end{array}$ & $\begin{array}{l}\text { Predominant emphysema } \\
\text { phenotype }(n=4 I)\end{array}$ & $\begin{array}{l}\text { Males } \\
(n=42)\end{array}$ & $\begin{array}{l}\text { Females } \\
(n=27)\end{array}$ \\
\hline \multirow{2}{*}{${ }_{\text {\%LAA }}^{-950 \text { insp }}$} & $r=-0.43$ & $r=-0.29$ & $r=-0.43$ & $r=-0.37$ & $r=-0.54$ \\
\hline & $P<0.00 I$ & NS & $P<0.0$ I & $P<0.05$ & $P<0.0$ I \\
\hline \multirow[t]{2}{*}{$\% L A_{-910 \exp }$} & $r=-0.57$ & $r=-0.54$ & $r=-0.37$ & $r=-0.46$ & $r=-0.57$ \\
\hline & $P<0.000 I$ & $P<0.01$ & $P<0.05$ & $P<0.01$ & $P<0.000$ I \\
\hline
\end{tabular}

Abbreviations: CT, computed tomography; \%LAA ${ }_{-910 x p}$, percentage of total lung area with attenuation values below -910 Hounsfield units at maximal expiration; \%LAA -950 insp, percentage of total lung area with attenuation values below -950 Hounsfield units at maximal inspiration; NS, not significant. 


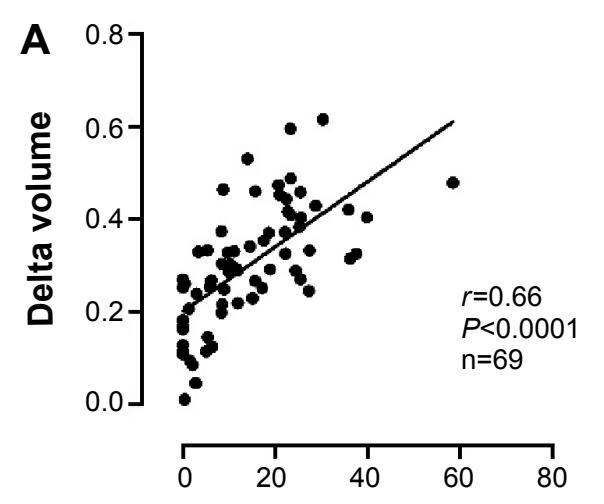

Intrathoracic tracheal collapsibility
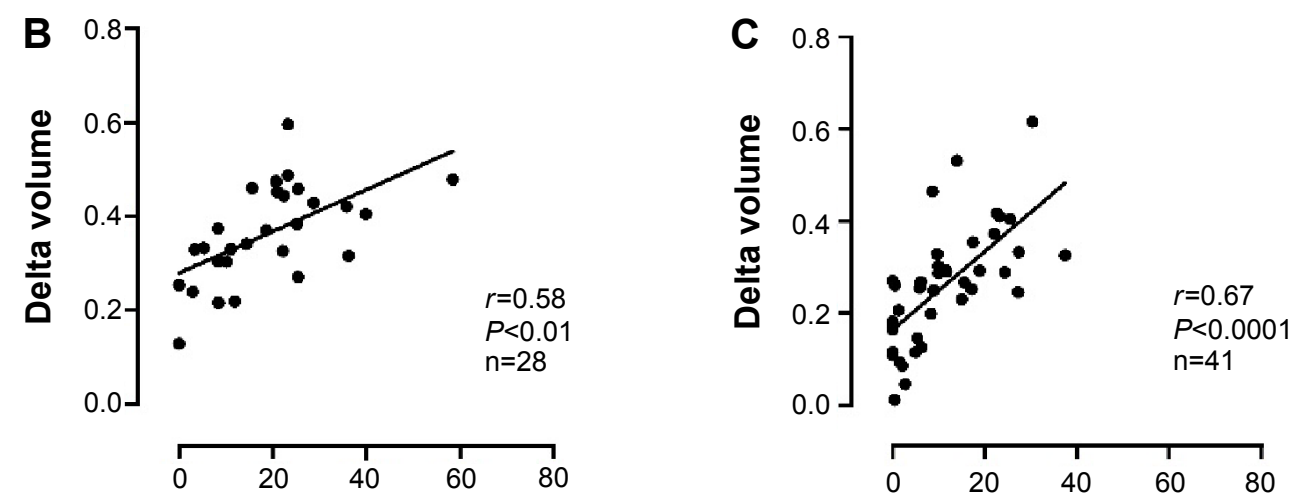

Intrathoracic tracheal collapsibility (predominant airway disease)

Intrathoracic tracheal collapsibility (predominant emphysema)
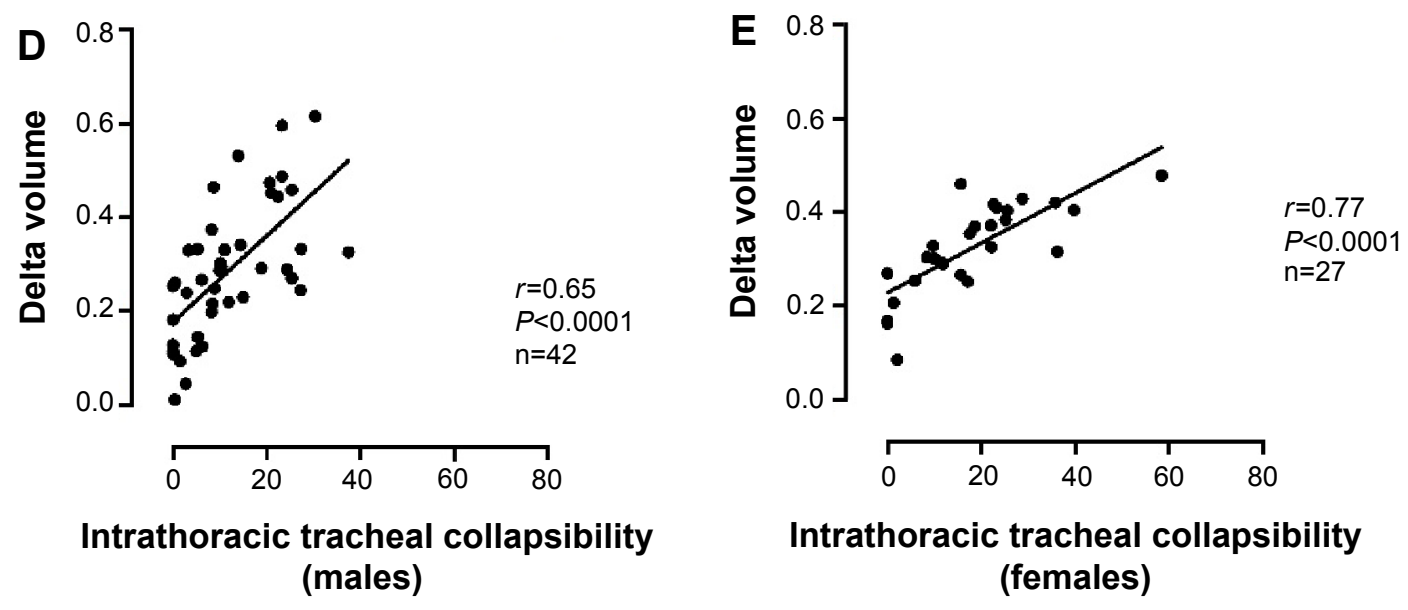

Intrathoracic tracheal collapsibility (females)

Figure 2 Relationship of intrathoracic tracheal collapsibility with delta volume ([inspiratory CT volume - expiratory CT volume]/inspiratory CT volume) in 69 patients with COPD (A); 28 of whom were classified as being affected by predominant airway disease (B); 41 of whom were classified as being affected by predominant emphysema (C); males (D); and females (E).

Abbreviations: COPD, chronic obstructive pulmonary disease; $\mathrm{CT}$, computed tomography.

\section{Discussion}

We found that intrathoracic tracheal collapsibility was increased in patients with a predominant airway phenotype of COPD, positively related with $\mathrm{FEV}_{1}$, and with changes in $\mathrm{CT}$ lung volume from the inspiratory to the expiratory scans, and negatively related with $\mathrm{FRC} \%$, with $\% \mathrm{LAA}_{-950 \text { insp }}$ and with \% $\mathrm{LAA}_{-910 \mathrm{exp}}$. Intrathoracic tracheal collapsibility was not related with common symptoms of COPD such as cough and wheezing. Intrathoracic tracheal collapsibility was significantly higher in females with respect to males. 


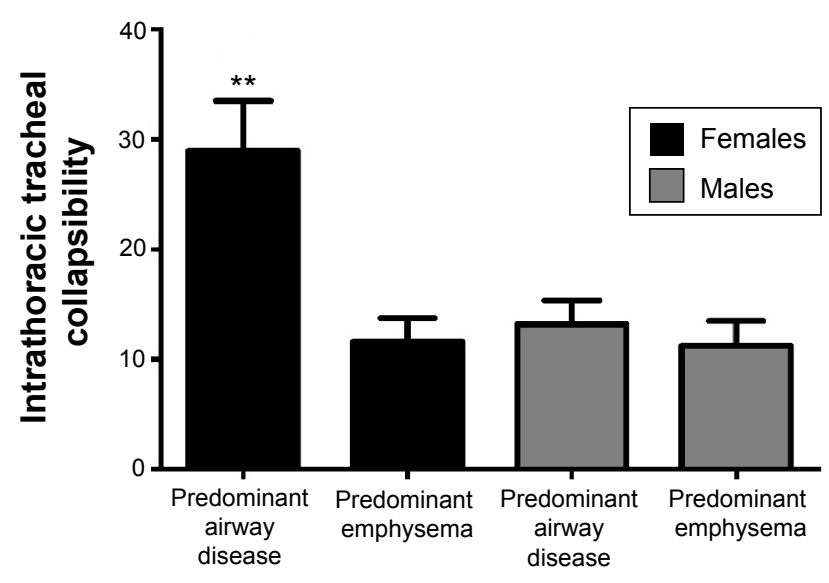

Figure 3 Intrathoracic tracheal collapsibility in males and females with COPD according to predominant airway disease and predominant emphysema. Note: $* * P<0.001$ among females.

Abbreviation: COPD, chronic obstructive pulmonary disease.

This finding was more evident in females with a predominant airway disease phenotype of COPD.

\section{Relationships of intrathoracic tracheal collapsibility with conductive airway disease phenotype and with functional and densitometric parameters}

The observation of a higher degree of intrathoracic tracheal collapsibility in patients with predominant airway disease confirms previous findings. ${ }^{6}$ This can been explained by the presence of a common inflammatory process involving upper

Table 5 Predictive models of intrathoracic tracheal collapsibility by multivariate regression analysis of clinical history data (cough, wheezing, dyspnea), pulmonary function, and CT variables in the whole set of patients with COPD and in the examined subsets

\begin{tabular}{|c|c|c|c|}
\hline $\begin{array}{l}\text { Estimates of intrathoracic } \\
\text { tracheal collapsibility }\end{array}$ & Predictors & Coefficients & $R / R^{2}$ \\
\hline \multirow[t]{3}{*}{ All patients $(n=69)$} & Delta volume & 49.6 & $0.70 / 0.49$ \\
\hline & $\%$ LAA $_{-910 \exp }$ & -0.217 & \\
\hline & Intercept & 2.176 & \\
\hline Predominant airway & Delta volume & 75.26 & $0.60 / 0.36$ \\
\hline phenotype $(n=28)$ & Intercept & -8.465 & \\
\hline Predominant & Delta volume & 36.46 & $0.78 / 0.6 I$ \\
\hline emphysema phenotype & BMI & 0.684 & \\
\hline \multirow[t]{2}{*}{$(n=4 I)$} & $\mathrm{FRC}$ & -0.089 & \\
\hline & Intercept & -2.445 & \\
\hline \multirow{3}{*}{ Males $(n=42)$} & Delta volume & 36.49 & $0.69 / 0.48$ \\
\hline & BMI & 0.648 & \\
\hline & Intercept & $-|4.8|$ & \\
\hline \multirow[t]{2}{*}{ Females $(n=27)$} & Delta volume & III.I & \\
\hline & Intercept & -17.96 & $0.7 / 10.59$ \\
\hline
\end{tabular}

Abbreviations: BMI, body mass index; COPD, chronic obstructive pulmonary disease; CT, computed tomography; FRC, functional residual capacity; \%LAA_910exp' percentage of total lung area with attenuation values below -910 Hounsfield units at maximal expiration. and lower airways and resulting in tracheal collapsibility and bronchial wall thickening in patients who have clinical and functional characteristics of predominant airway disease. It has been reported that chronic cough, the most frequent symptom in COPD patients with predominant airway disease, could cause repeated mechanical stress with stretching and degeneration of the posterior membranous portion of the trachea. ${ }^{20}$

Similarly to what has been found by Han et al in the COPDGene study, ${ }^{10}$ our patients with predominant airway disease were affected by a less severe form of COPD with respect to those affected by emphysema.

That intrathoracic tracheal collapsibility reflects not only the degree of airway obstruction but also lung volume and lung emptying during expiration is shown by its positive correlation with $\mathrm{FEV}_{1}$ and with delta volume, the predictive value of delta volume at multivariate analysis, and the negative relationship with $\mathrm{FRC}_{0}, \mathrm{oLAA}_{-910 \mathrm{exp}}$, and $\% \mathrm{LAA}_{-950 \text { insp }}$. In other words, intrathoracic tracheal volume reduction (collapsibility) and lung volume reduction (delta volume) from maximal inspiration to maximal expiration are proportional, and tracheal collapsibility expresses the capability of the lungs to deflate during expiration. In fact, expiratory lung volume reduction is significantly lower in patients with emphysema and tends to be lower in males with respect to females as reported in Table 2.

This confirms previous findings of Yamashiro et $\mathrm{a}^{21}$ and supports the view that hyperinflated patients have small changes in lung volume during the respiratory cycle, and, as a consequence, the intrathoracic pressure and tracheal size at end expiration do not change significantly with respect to inspiration. The overinflated lung of the emphysematous patients could indeed be assimilated to a stiff system, where the altered mechanic and elastic properties do allow neither significant parenchymal inflation and deflation nor tracheal collapsibility during the respiratory cycle. This hypothesis is strongly supported both by the positive relationship between tracheal collapsibility and delta volume and by the negative relationship between tracheal collapsibility with FRC \% and $\%$ LAA.

In a very recent paper, Boiselle et $\mathrm{a}^{22}$ described a significant association of tracheal collapsibility with obesity in COPD. This finding could be at least in part ascribed to the lung volume changes caused by obesity. In these patients FRC is often near the lower limit of normality or slightly abnormal, and patients often display clinical and functional features of predominant airway phenotype of COPD. 
Our results are in contrast with those of Boiselle et $\mathrm{a}^{23}$ and Sverzellati et $\mathrm{al}^{6}$ who did not find any correlation between lung function and the magnitude of tracheal collapsibility measured at the end of forced expiration. In both studies, forced expiratory maneuvers alone could have reduced lung emptying ${ }^{12}$ by shortening expiratory time and causing early airways closure. This could be accentuated by both severe obstruction and supine position. Furthermore, during forced inspiratory-expiratory maneuvers, intrathoracic tracheal collapsibility might be influenced by the relative force of the expiratory and inspiratory muscles. We have no direct measurement of the respiratory muscle strength in our patients; however, we observed that BMI was significantly lower in patients with predominant emphysema (Table 1) and that it was an independent predictor of intrathoracic tracheal collapsibility in this phenotype (Table 5). This could imply also that patients with reduced BMI could have reduced muscle strength to perform forced maneuvers. In this connection, the static technique we have used could be appropriate for hyperinflated patients.

\section{Intrathoracic tracheal collapsibility is not related to clinical features of COPD}

The lack of relationship between cough, wheezing, and intrathoracic tracheal collapsibility is another important finding of our paper. A significantly higher dyspnea perception measured by mMRC scale has been found in patients with an emphysematous phenotype and a lower degree of intrathoracic tracheal collapsibility. These findings are in keeping with recently published data showing a wide spectrum of tracheal collapse also among healthy volunteers without respiratory symptoms. ${ }^{8}$ This last result and the direct relationship between intrathoracic tracheal collapsibility and $\mathrm{FEV}_{1} \%$, suggest that the magnitude of expiratory tracheal collapsibility is associated with less impaired lung function and could not be linked to a pathologic process.

\section{Intrathoracic tracheal collapsibility is more frequent in women with COPD}

In this series of COPD patients, women showed a significantly higher degree of tracheal collapsibility than men. The highest tracheal collapsibility was observed in women with a predominant airway phenotype. Taking into account that the proportion of predominant airway and predominant emphysema phenotype of COPD was the same in women and men, this finding could suggest a sex effect on tracheal collapsibility; on the other hand, we cannot exclude that the high degree of intrathoracic tracheal collapsibility in women could be due to a better preserved lung function, with a significantly lower degree of airway obstruction and of emphysema at CT. This finding was confirmed when comparing tracheal collapsibility and lung function in the whole set of patients, and it is in agreement with the results of another study in which a high degree of tracheal collapsibility was found in healthy young women as compared to men. ${ }^{24}$ Although the higher level of tracheal collapsibility in women could be included among the different sex-based expressions of COPD, our results cannot be conclusive considering the low number of observation. Other studies have shown that women have both smaller airways' lumina and thicker bronchial wall and tend to exacerbate more frequently than men..$^{10,11}$

We found, as already reported by Kim et $\mathrm{a}^{25}$ that airway wall thickness measured by AWTPi10 was lower in women with respect to men. Remarkably, the values of AWTPi10 found in this study for men and women had the same mean value of those found by Kim et al. ${ }^{25}$ On the other hand, other studies demonstrated that women had higher wall thickness in the subsegmental and subsubsegmental paths, through all Global Initiative for Chronic Obstructive Lung Disease stages. ${ }^{10,11}$ Thus, in regard to whether airways are thicker in men compared to women, we have to first consider what definition of airway dimension are employed. Anyway, further studies will be needed to clarify these discrepancies and their clinical relevance, and to evaluate which airway parameter measured at CT could be more relevant in clinical setting.

We recognize that this study has some limitations. First, as in most studies on this subject, ${ }^{6,7,23,24}$ the value of the results obtained is limited by the small sample of COPD patients recruited. Second, we acquired expiratory scans at the end of a maneuver of slow vital capacity, which could be a less sensitive technique, ${ }^{7}$ underestimating tracheal collapsibility with respect to dynamic expiratory scans. ${ }^{26}$ Nevertheless, the significant differences we obtained in intrathoracic tracheal collapsibility will be amplified with the more sensitive dynamic acquisition technique. Moreover, the end-expiratory scans we used have been proved to be effective to study patients with COPD. ${ }^{21,27,28}$ Third, we investigated the degree of intrathoracic tracheal collapsibility in COPD without establishing a threshold value for excessive tracheal collapsibility or tracheomalacia. High threshold values up to $50 \%$ or $80 \%$ of expiratory reduction in tracheal cross-sectional area have been proposed to define excess of tracheal collapsibility in healthy subjects and patients scanned with dynamic expiration. ${ }^{6,23}$ Two lower thresholds to define excessive tracheal collapsibility have been proposed by Aquino et $\mathrm{al}^{29}$ who used end expiratory CT scans. In ten patients, they obtained 
a positive predictive value of $89 \%-100 \%$ for tracheomalacia by using a threshold of more than $18 \%$ collapse for the upper trachea and of more than $28 \%$ for the mid-trachea. The magnitude of tracheal collapsibility data obtained in the Aquino et $\mathrm{al}^{29}$ study, obtained with a slow vital capacity maneuver, fits well with the range of measurements of intrathoracic tracheal collapsibility found in this study.

\section{Clinical implications}

The finding of intrathoracic tracheal collapsibility at CT in patients with COPD is frequent, often incidental, and not correlated with symptoms. This implies that no treatment is required if there are no symptoms. In the presence of bronchospasm, this must be controlled as it could result in large pressure swings in the thorax with increased degree of intrathoracic tracheal collapsibility, increased airway resistance, and work of breathing. A complete functional assessment, a 6-minute walking test, and a quality of life questionnaire administration have been suggested ${ }^{1}$ to evaluate objectively the results of interventions. Treatment with noninvasive positive ventilation or with stenting or other surgical procedures should be considered in highly symptomatic patients not responsive to a conservative approach. ${ }^{1}$

\section{Conclusion}

Intrathoracic tracheal collapsibility and clinical phenotypes of COPD are closely correlated. In patients with a predominant emphysematous phenotype, a less collapsible trachea reflects the mechanical properties of the stiff hyperinflated emphysematous lung. The higher degree of tracheal collapsibility found in patients with predominant airway disease, mild airway obstruction, and in women with this phenotype confirms the above mentioned finding. The lack of relationship between intrathoracic tracheal collapsibility and symptoms could indicate that this radiologic finding by itself should not be considered as an abnormal feature, and it should not be necessarily a pathologically relevant finding in patients with COPD.

\section{Acknowledgment}

This work was funded by a Research Project of the Italian Ministry of Health (project code RF-2010-2321362).

\section{Disclosure}

Doctors Camiciottoli and Diciotti were responsible for the funds allocation of the grant obtained by the Italian Ministry of Health. The other authors report no conflicts of interest in this work.

\section{References}

1. Carden KA, Boiselle PM, Waltz DA, Ernst A. Tracheomalacia and tracheobronchomalacia in children and adults: an in-depth review. Chest. 2005;127(3):984-1005.

2. Boiselle PM. Tracheomalacia: functional imaging of the large airways with multidetector-row CT. In: Boiselle PM, White CS, editors. New Techniques in Cardiothoracic Imaging. New York, NY: Informa; 2007:177-185.

3. Fraser RS, Colman N, Müller NL, Paré PD. Upper airway obstruction. In: Fraser RS, Colman N, Müller NL, Paré PD, editors. Synopsis of Diseases of the Chest. 4th ed. Philadelphia, PA: Saunders; 1999:2042-2046.

4. Lee KS, Sun MR, Ernst A, Feller-Kopman D, Majid A, Boiselle PM. Comparison of dynamic expiratory $\mathrm{CT}$ with bronchoscopy for diagnosing airway malacia: a pilot evaluation. Chest. 2007;131(3):758-764.

5. Gilkeson RC, Ciancibello LM, Hejal RB, Montenegro HD, Lange P. Tracheobronchomalacia: dynamic airway evaluation with multidetector CT. AJR Am J Roentgenol. 2001;176(1):205-210.

6. Sverzellati N, Rastelli A, Chetta A, et al. Airway malacia in chronic obstructive pulmonary disease: prevalence, morphology and relationship with emphysema, bronchiectasis and bronchial wall thickening. Eur Radiol. 2009;19(7):1669-1678.

7. Yamashiro T, San José Estépar R, Matsuoka S, et al. Intrathoracic tracheal volume and collapsibility on inspiratory and end-expiratory ct scans correlations with lung volume and pulmonary function in 85 smokers. Acad Radiol. 2011;18(3):299-305.

8. Boiselle PM, O'Donnell CR, Bankier AA, et al. Tracheal collapsibility in healthy volunteers during forced expiration: assessment with multidetector CT. Radiology. 2009;252(1):255-262.

9. Camiciottoli G, Cavigli E, Grassi L, et al. Prevalence and correlates of pulmonary emphysema in smokers and former smokers. A densitometric study of participants in the ITALUNG trial. Eur Radiol. 2009;19(1): $58-66$.

10. Han MK, Kazerooni EA, Lynch DA, et al; COPDGene Investigators. Chronic obstructive pulmonary disease exacerbations in the COPDGene study: associated radiologic phenotypes. Radiology. 2011;261(1): 274-282.

11. Grydeland TB, Dirksen A, Coxson HO, et al. Quantitative computed tomography: emphysema and airway wall thickness by sex, age and smoking. Eur Respir J. 2009;34(4):858-865.

12. Pellegrino R, Viegi G, Brusasco V, et al. Interpretative strategies for lung function tests. Eur Respir J. 2005;26(5):948-968.

13. Camiciottoli G, Bigazzi F, Paoletti M, Cestelli L, Lavorini F, Pistolesi M. Pulmonary function and sputum characteristics predict computed tomography phenotype and severity of COPD. Eur Respir J. 2013;42(3): 626-635.

14. Stoel BC, Stolk J. Optimization and standardization of lung densitometry in the assessment of pulmonary emphysema. Invest Radiol. 2004; 39(11):681-688.

15. Parr DG, Stoel BC, Stolk J, Nightingale PG, Stockley RA. Influence of calibration on densitometric studies of emphysema progression using computed tomography. Am J Respir Crit Care Med. 2004;170(8): 883-890.

16. Diciotti S, Sverzellati N, Kauczor HU, et al. Defining the intra-subject variability of whole-lung $\mathrm{CT}$ densitometry in two lung cancer screening trials. Acad Radiol. 2011;18(11):1403-1411.

17. Kalender WA, Fichte H, Bautz W, Skalej M. Semiautomatic evaluation procedures for quantitative CT of the lung. J Comput Assist Tomogr. 1991; 15(2):248-255.

18. Gevenois PA, de Maertelaer V, De Vuyst P, Zanen J, Yernault JC. Comparison of computed density and macroscopic morphometry in pulmonary emphysema. Am J Respir Crit Care Med. 1995;152(2):653-657.

19. Orlandi I, Moroni C, Camiciottoli G, et al. Chronic obstructive pulmonary disease: thin-section CT measurement of airway wall thickness and lung attenuation. Radiology. 2005;234(2):604-610.

20. Loring SH, O'donnell CR, Feller-Kopman DJ, Ernst A. Central airway mechanics and flow limitation in acquired tracheobronchomalacia Chest. 2007;131(4):1118-1124. 
21. Yamashiro T, Matsuoka S, Bartholmai BJ, et al. Collapsibility of lung volume by paired inspiratory and expiratory CT scans: correlations with lung function and mean lung density. Acad Radiol. 2010; 17(4):489-495.

22. Boiselle PM, Litmanovich DE, Michaud G, et al. Dynamic expiratory tracheal collapse in morbidly obese COPD patients. COPD. 2013; 10(5):604-610.

23. Boiselle PM, Michaud G, Roberts DH, et al. Dynamic expiratory tracheal collapse in COPD: correlation with clinical and physiologic parameters. Chest. 2012;142(6):1539-1544.

24. O'Donnell CR, Litmanovich D, Loring SH, Boiselle PM. Age and sex dependence of forced expiratory central airway collapse in healthy volunteers. Chest. 2012;142(1):168-174.

25. Kim YI, Schroeder J, Lynch D; Copdgene Investigators. Gender differences of airway dimensions in anatomically matched sites on CT in smokers. COPD. 2011;8(4):285-292.
26. O’Donnell CR, Bankier AA, O’Donnell DH, Loring SH, Boiselle PM. Static end-expiratory and dynamic forced expiratory tracheal collapse in COPD. Clin Radiol. 2014;69(4):357-362.

27. Akira M, Toyokawa K, Inoue Y, Arai T. Quantitative CT in chronic obstructive pulmonary disease: inspiratory and expiratory assessment. AJR Am J Roentgenol. 2009;192(1):267-272.

28. Matsuoka S, Kurihara Y, Yagihashi K, Hoshino M, Nakajima Y. Airway dimensions at inspiratory and expiratory multisection $\mathrm{CT}$ in chronic obstructive pulmonary disease: correlation with airflow limitation. Radiology. 2008;248(3):1042-1049.

29. Aquino SL, Shepard JA, Ginns LC, et al. Acquired tracheomalacia: detection by expiratory CT scan. J Comput Assist Tomogr. 2001; 25(3):394-399.

\section{Publish your work in this journal}

The International Journal of COPD is an international, peer-reviewed journal of therapeutics and pharmacology focusing on concise rapid reporting of clinical studies and reviews in COPD. Special focus is given to the pathophysiological processes underlying the disease, intervention programs, patient focused education, and self management protocols.

\section{Dovepress}

This journal is indexed on PubMed Central, MedLine and CAS. The manuscript management system is completely online and includes a very quick and fair peer-review system, which is all easy to use. Visit $\mathrm{http}: / / \mathrm{www}$. dovepress.com/testimonials.php to read real quotes from published authors.

Submit your manuscript here: http://www.dovepress.com/international-journal-of-chronic-obstructive-pulmonary-disease-journal 